\title{
The post-pandemic blended university in the time of digitisation
}

\section{Philip Uys and Mike Douse}

\begin{abstract}
This paper documents the inevitable emergence of the 'Global School', assesses how the COVID-19 pandemic is hastening that transformation, and then focusses upon how these elemental educational developments may apply at the post-school level. Digitisation involves a pivotal leap in human potential as profound as the wheel in terms of development, as significant as the book in relation to information, and as iconoclastic as anything dreamed up by the deepest analyst/therapist in terms of the human psyche. Given that we are moving inexorably and joyfully into the One World One School situation, do we envisage the one global and blended university - where universal access and organisation are intermingled with local needs, cultures and priorities? Are we also progressing towards a blended postsecondary assessment and learning pedagogy in which the digital is dominant? And, if so, how will the pandemic - and the responses to it - pave the way towards that desirable destination?
\end{abstract}

Keywords: Global School, Digitalisation, Digitisation, Digitalization, Blended University, COVID, Pandemic, Smart University.

\section{Preamble}

In the mid-1960s, one of the present authors was condescending and foolhardy enough to announce that the most prestigious academic qualification available in Australia was a London University external degree. A few years subsequently, when Harold Wilson's emissaries visited Australia seeking models for the UK's emerging Open University, it was he who escorted them to Armidale where they gained much of practical value from UNE's distance learning experiences (Douse, 1973).

Half a century on, education is undergoing a fundamental transformation consequent upon the challenges and possibilities of the Digital Age and responding to the tangible/virtual duality of contemporary consciousness. The manner in which the transmission of information (and the terrifyingly glorious vastness of readily-available data out of which, skillfully, such information may be derived) and the sharing of ideas and the stimulation of creativity may be achieved, manifest a fresh socio-economic as well as educational era - a transition as epochshattering as that from feudalism to capitalism. We are moving inexorably and joyfully towards the Global School: the COVID-19 pandemic may open up a short cut to that destination. Having first clarified what this entails for schools, we shall then explore the implications for universities.

\section{The Global School}

The present authors have spoken and written extensively on the forthcoming and fundamental transformation of schooling, definitively described and defended in their recent publication One World One School (Douse \& Uys, 2020a). Schools, as we know them, are an industrial age phenomenon (with ecclesiastical antecedents). In this contemporary world, characterised by connectivity, exemplified by immediacy and defined by self-determined information access, they are as outdated as are slavery, droit du seigneur and facsimile machines.

We have explained how education needs to be totally restructured with Digitisation as the cohesive force so as to achieve its potential and create previously unimagined synergies. We have detailed how attempting to incorporate isolated applications into essentially second millennium institutions and systems has resulted in four decades of disappointment. We have called for an entire overhaul, moving above AI and beyond ICT, embodying and synergistically integrating contemporary technology in its connectivity, organisation, curriculum content and research, and in innovation, learning methods and management - see Figure 1. By no means the End of History - more, at least educationally, the Overcoming of Geography.

The Global School's essential, integrated and mutually-supportive components comprise:

- Learners: active, engaged, for life, committed to personal development, self-directed, information and digitally 
literate, research-capable, mobile, collaborating, sharing their learning globally;

- Connectivity: easy, rapid, reliable, uninterrupted and affordable (i.e., free) access worldwide utilising appropriate mobile appliances for every learner [unspecifiable here, as there will be rapid changes in handling, versatility, online support methodologies and cost minimisation];

- Teachers: well-prepared and well-led professional educators, delivering, facilitating and assessing digitally delivered learning, at ease with the technology, guiding, supporting and counselling the learners, sharing their learning materials globally;

- Curriculum: responding to learners' well-informed preferences, attractive, contemporary and proven learning modules (with teachers' guides) at all levels in all subjects, in every relevant language, plus background materials, further reading, in ineffable variety;

- Pedagogy: geared to supporting learners whether face-to-face or at a distance, far from test-obsessed, encouraging enjoyment and the thrill of exploration and discovery, engendering a lifetime love of learning;

- Inclusion: all learners worldwide, full- and part-time, on-campus and distant, irrespective of age, gender, beliefs, abilities or disabilities, are welcomed equitably and individually catered for; and

- System: geared to optimising enjoyable learning through, for example, exemplary educational institutional leadership, the continuous professional development of teachers, participation of family and community, and stimulating extra-curricular activities.

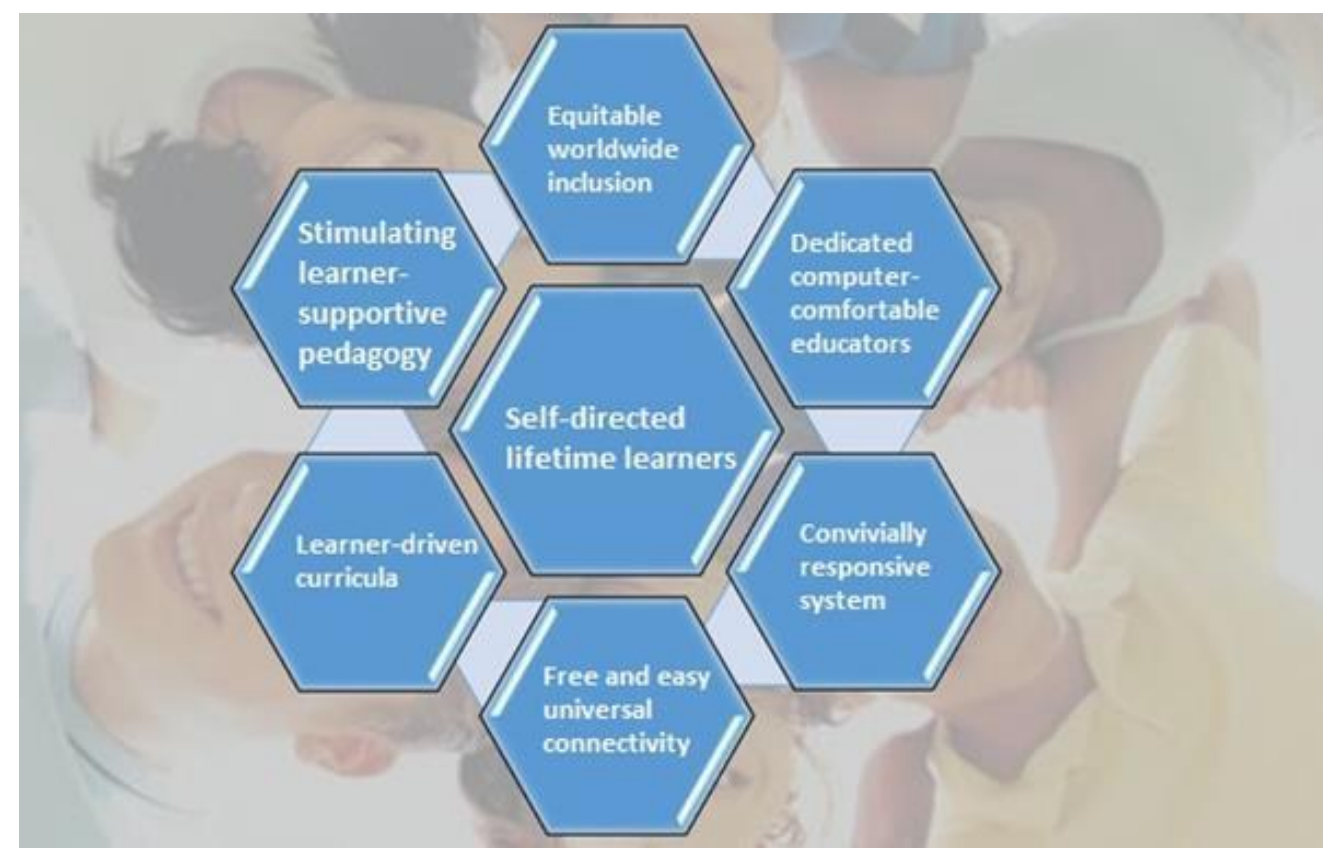

Figure 1: The Global School

Let us draw an analogy. For over two millennia, there have been numerous discrete libraries, each tied to a physical location, each providing valued services (predominantly books - originally hand-crafted) to their particular customers (initially theologians). But now, with Digitisation, it is sensible to conceive of just the one fully-connected worldwide library (the 'Global Library'), enabling any user anywhere to access information, to contribute to the vast body of facts and ideas and, indeed, to print out items or download books and journals for private study and enjoyment on hand-held and other personal devices. This is indeed already a reality with the advent of the Word Wide Web, the concept of the Cloud, as well as the integration of numerous databases into single portals where it does not matter to the student where the file resides but simply that it meets their requirements for learning and research. And, in a similar way, instead of multifarious and isolated educational institutions of varying natures, locations, qualities and aspirations, with Digitisation it is now feasible and necessary to think of the Global School as the one (soon to be) fully-connected and networked worldwide educational institution.

Alongside the actual, the virtual will from now and henceforth be a vital and integrated element of everyone's everyday education: so central to teaching and learning that it becomes indistinguishable from the more traditional components. In terms of secondary and lifelong learning, we have shown that contemporary (i.e., 
outdated) education systems often remain geared to providing compliant labour to increase the wealth of a few, tailoring people to the workplace, and engendering the false notion of education as human resource investment. Such second millennium schools, predicated upon preparation for adulthood, based upon externally imposed curricula and teacher-centered pedagogies, sorting out rather than serving their students, are antediluvian. They may now be washed away by the flood of possibilities arriving by the tides of contemporary technology, expertly navigated by teachers, planners, educational philosophers, far-sighted world citizens and, above all, by learners increasingly conscious of, and progressively demanding worldwide educational support appropriate to the Digital Age.

Billions of learners are yearning for education. Instead, nine-tenths of them are fobbed off with job preparation and discriminatory job preparation at that. Most young people worldwide are being lulled into subservience, distracted by job market distortions, robbed of genuine education in favour of job readiness fabrications. Far from education being a preparation for the world of work, the only reason for working hard, for getting a wellpaid job and for accumulating wealth is to be able to devote oneself to obtaining the most self-fulfilling possible lifelong education. What young people - all people - should be helped to acquire are the multiliteracies of the Digital Age (UN ESCO, 2020), the facility of deciding what they want to learn, and to enjoy learning, in the present-day, evolving context.

\section{Education in the time of COVID-19}

The present authors have, very recently, addressed the issue of the pandemic's potential role in furthering the fundamental transformation, addressing COVID-19 and the Demise of 'The School' (Douse \& Uys, 2020b). Our conclusion was that the urgent actions consequent upon the present pandemic offer a short-cut into that transformed educational situation within which 'The School' as we know it will fade into history.

From March 2020, the novel Coronavirus pandemic began to dominate the news, everyone's conversation and both the local and the national personal and public health situations. 'Getting our schools back to normal' appeared to be the worldwide aspiration, albeit acknowledging co-existence with the virus on a long-term basis, and typically (in many Western countries) as if schooling were predominantly a combination of child-minding and university selection. But all of that vain effort was based upon the false presupposition that the mission was to restore education to its pre-pandemic situation where the use of digital technologies were often treated as a possible add-on based on the personal preferences of teachers at all levels of education. Blending online and face-to-face learning was thus not based on the affordances of these modalities and thus strengthening the learning and assessment, but simply the personal preferences of most teachers. However, prior to COVID-19's emergence, many schools worldwide were already commencing their fundamental transformation, made necessary and possible by Digital Age technology. The digital divide is to be treated very seriously, yet many developing countries have developed effective strategies to close that gap such as national agreements with Internet Service Providers to allow free access for learning purposes, use of Open Education Resources (OER) and laptop and tablet lending schemes to students and staff. Responses to the coronavirus challenge need to be consistent with that underlying, permanent and more profound conversion.

Educationally, COVID-19 is an opportunity (as well as an unquestionable disaster). It could well be that postpandemic, our world, our societies and our economies will be utterly transformed. Given that 'the school', as presently manifest and conceptualised, is facing its demise, it could well be that - for all its horrific aspects - the novel Coronavirus offers the catalyst to that development. And so, we urged, let us use these COVID-19 months (and their aftermath) imaginatively, positively and well - not to return to the previous status quo, but rather to achieve a blended assessment and learning model where online and face-to-face pedagogies are integrated to create new synergies for the 'school'. And, above all, let us recognise that, just as nothing will ever be the same - economically and socially - post-pandemic, so also will nothing - educationally - ever be the same again post - Digitisation.

\section{Towards the Universal University?}

But to what extent, if at all, does the holus bolus transition - and, hence, COVID-19's impact upon it - apply at the post-secondary level? Universities are in part vocational training centres and in part educational institutions. But those who attend them specifically in order to become lawyers, teachers, doctors, accountants, nurses and software engineers gain also what some refer to as a 'liberal education' just as those who seek primarily the 'university experience' may well - as a practically valuable spin-off - find themselves becoming more 
marketable job-wise.

Hopefully, there will always be communities of scholars extending the boundaries of knowledge. As Stefan Collini puts it, "we exercise true democratic accountability, not by trying to subordinate universities to the current favoured form of economic policy, but by ensuring that they are enabled to concentrate upon their principal task of extending and deepening human understanding, because it is from the successful pursuit of that task that, in the long term, society as a whole derives the greatest benefit" (Collini, 2018).

The many thoughtful considerations of 'smart universities' (Stracke, Shanks \& Tveiten, 2018) - defined in this instance as "those educational institutions that adopt to the realities of digital online media in an encompassing manner" - concentrate upon the emergent uses of communications technologies in learning, recognising that the challenge of understanding goes to the core of institutions and organisations as much as pedagogy and practice in the classroom. As those authors make clear, the emphasis is upon "the effects of learning technologies, texts and aesthetics, personalised learning experience, new means of assessments, the potentials of globalised learning networks... Smart universities transfer the innovative process from the drawing board and the tools at hand to the learning designs that in turn reflect on human interaction" (Stracke, Shanks \& Tveiten, 2018). A blended assessment and learning model based on Digitisation, similarly, may reside in a blended university: one where Digitisation allows it to be truly universal but blended with local support, culture, needs and priorities.

Universities are, as are so many other veritable institutions these days, businesses: even those most sheltered from market forces are generally expected to be commercially responsive, profitable and market relevant. The most prestigious are akin to hedge funds with their endowments running into billions - and their Vice Chancellors paid in the millions - and, in such circumstances, expecting ethical enrichment is unrealistic. Transnational higher education has become a major industry and, in a linked and competitive world, how could such displays of entrepreneurial initiative not come to pass? Equally, how could such a business basis survive the restrictions consequent upon the novel Coronavirus? How can a business plan predicated upon international students being present on campus in person in substantial numbers, succeed in the time of the pandemic? And the significant drop off of international students - particularly from China and India - because of closed national borders due to this pandemic, has already caused major financial deficits for some universities and consequent job losses.

But comprehensive tertiary institutions and systems may now, and at last, embody the true universitas spirit, those business orientations notwithstanding. Whatever the mechanism, and however the occupational kaleidoscope settles at any point in the flow of time, the massive, multifarious, and dynamic requirement for (a) education and (b) lifelong skills development will need to be met, creatively, efficiently, and, hopefully, equitably and, of course, unconfined by national boundaries, and based on Digitisation. And all of that to be envisaged and achieved, let it also be emphasised, not by remote coteries of sequestered decision-makers with noble intentions unmatched by close acquaintance with reality but by means of the kind of well-informed universal participation blended with, and informed by local needs that, at its best, contemporary technology makes possible, enjoyable, and unavoidable.

\section{The University in the time of (and post-) pandemic}

With the novel Coronavirus, everything has changed dramatically: hitherto unknown health, economic, social, technological, and educational challenges have emerged, although the post-pandemic 'normalcy' is far from clear. Already, Australia's universities, in common with many of those elsewhere, are responding to their perceptions of those challenges: perhaps more reactively and in relation to specific issues (e.g., overseas students) than coherently, creatively and proactively - but that is understandable. However, this major set of inter-related changes is occurring within a fundamental transformation of all education and so, in that sense, the challenges of COVID-19 offer a pathway to the forthcoming and fundamentally transformed higher education sector worldwide. Let us understand and seize that opportunity so that a universal university blended with local prerogatives will emerge as part of global partnerships also for better disaster preparedness (Commonwealth of Learning, 2020).

One of the present authors (Uys, 2020) has reflected upon lessons learned during the present pandemic about ensuring quality in online assessment particularly in dealing with traditional exams (as traditional tests, assignments and gradebooks were quite easily transferred online). Successful strategies include diversification, using interactive oral assessments via web-conferencing, using online proctored exams from home, using 
"Practice tests/exams" or "Try It Out" exams, breaking up exams into smaller quizzes, using open book exams with randomised questions and providing multiple scenarios. In addition to exam anxiety, there is also technology anxiety that requires communication and change management activities. Due to the flexibility for all and students welcoming typing (not writing!), such online assessment strategies will blend post-pandemic with a small percentage of face-to-face assessment strategies.

Dr Kwong Nui Sim (2020) discusses flexible teaching and learning "during this critical global time of the COVID-19 outbreak" noting the lack of "pedagogies that underpin this process along with the shared understanding" and calling for a "consideration of all aspects of teaching and learning (so that there might be) a silver lining in this disaster that should be able to change our minds without infecting our lungs" (Sim, 2020). The quality of practical courses and work-based learning and placements have been enhanced through virtual simulation and have been significantly replaced by digital activities. Well-designed fully online courses though require a much less prominent role for teachers. The term “blended learning” has existed since the early 2000's and has been interpreted in various ways (Oliver \& Trigwell, 2005) and has often been misused to justify traditional teaching with a small percentage of digital thrown in. We posit that the blended pedagogical approaches above in which digital is dominant will be retained as students, teachers and institutions reflect on what they have been learning during the pandemic and not simply return to their former ways (McAleavy \& Gorgen, 2020; Uys, 2020).

Steven Jones (2020) observes that "Already, old ways of working seem distant and inexplicable. Were there really so many face-to-face meetings? What did all that bureaucracy achieve? Why did universities submit to so many external metrics? ... (The students) whom I'm now Skyping care little about "value for money" or expected graduate incomes. They are just glad that their learning still matters, and that university staff care about them".

Responding optimally to our new and entirely inter-connected and digitally based world necessitates and enables utterly original understandings, approaches, arrangements and aspirations as encapsulated in blended assessment and learning pedagogy. It involves the recognition that we are in a time of unparalleled challenges and opportunities and that, as a starting-point, we can and must agree upon a fresh comprehension of what education is really for in this third millennium and indeed beyond. Our remote ancestors stumbled upon tools to ward off predators, to enable agriculture, to play games and to express themselves on cave walls. We now devise tools that diminish both our need for tools and our ability to use them to good effect. Our elaborate $21 \mathrm{st}$ century digital devices are extensions of our evolving selves, codified in machines and infrastructures, manifest in frameworks of knowledge and action in a deeply personal yet universal way. Technology and Biology: Who Shall be Master? The psychology is the biology, and the education is the unifying pathway.

As one central and vital illustration (and with due respect of ASCILITE organisers), let it be clear that we should no longer be talking of 'Innovation, Practice and Research in the Use of Educational Technologies in Tertiary Education' but simply 'Innovation, Practice and Research in Tertiary Education'. Any time we address 'Tertiary Education' we are inevitably addressing 'Tertiary Education in the context of Educational Technologies' and therefore adding those words is redundant (just as we need not say 'Education including Books'). Failing to recognise and apply this Third Millennium truth undermines the discipline to which most of those present have devoted much of our lives and which we have come, albeit virtually, to Armidale to celebrate.

\section{Conceivable Scenarios}

In a sense, every higher education institution perceives itself as special: this one being characterised by whitehot technology, that by ivy-covered lecturers in ivy-covered halls. This university deserves its reputation for student support and welfare, that one has researchers at the forefront of the worldwide search for truth (or for lucrative patents). Clearly, there is a tension between this kind of localised exceptionalism and the opportunities for benefitting from similarities that allows a Universal University, and that call s for a blended University. Our initial consideration of each university element's 'virtual potentiality' (and hence 'international conceivability') is tabulated - as (let it be emphasised) a basis for discussion:

\begin{tabular}{|l|l|l|}
\hline Category & Illustrations & Online- ability \\
\hline
\end{tabular}




\begin{tabular}{|c|c|c|}
\hline $\begin{array}{l}\text { Large-scale ideas \& } \\
\text { information sharing }\end{array}$ & $\begin{array}{l}\text { Lectures covering languages, the humanities, law, the social and much } \\
\text { of physical and biological sciences; dissemination of reading matter... }\end{array}$ & Very high \\
\hline $\begin{array}{l}\text { Small -scale ideas \& } \\
\text { information sharing }\end{array}$ & $\begin{array}{l}\text { Tutorials, seminars, exchanges between students and between staff and } \\
\text { students, joint projects... }\end{array}$ & High \\
\hline $\begin{array}{l}\text { Hands-on learning and } \\
\text { practical work }\end{array}$ & $\begin{array}{l}\text { dLaboratory sessions, hospital and construction site experience, } \\
\text { attachments and internships, digital immersive learning and virtual } \\
\text { simulations, online conferencing, ... }\end{array}$ & $\begin{array}{l}\text { Increasingly } \\
\text { feasible - with } \\
\text { much creativity }\end{array}$ \\
\hline $\begin{array}{l}\text { Social interactions \& } \\
\text { communal activities }\end{array}$ & $\begin{array}{l}\text { Sport, clubs and societies, student magazines and drama - the } \\
\text { 'university experience' from Fresher's Week through to the Graduation } \\
\text { Ball... }\end{array}$ & $\begin{array}{l}\text { Quite high - } \\
\text { with } \\
\text { creativity }\end{array}$ \\
\hline $\begin{array}{l}\text { Academic guidance \& } \\
\text { formative assessment }\end{array}$ & $\begin{array}{l}\text { Setting, preparing, submitting, assessing and feedback on assignments; } \\
\text { module completion; course requirements and advice... }\end{array}$ & $\begin{array}{l}\text { Quite high - } \\
\text { with } \\
\text { creativity }\end{array}$ \\
\hline $\begin{array}{l}\text { Research, publication } \\
\& \text { conferences }\end{array}$ & $\begin{array}{l}\text { A warding, funding, monitoring and outcomes of grants; virtual and } \\
\text { tangible publication; community service; events such as the virtual } 2020 \\
\text { A SCIL ITE }\end{array}$ & 0 High \\
\hline $\begin{array}{l}\text { Accreditation \& } \\
\text { reputation }\end{array}$ & $\begin{array}{l}\text { Contributing to the formal certification of doctors, engineers and many } \\
\text { other categories of professional. Standing as a 'reputable' and 'leading' } \\
\text { institution. }\end{array}$ & Low \\
\hline
\end{tabular}

As open universities and professional societies (not to mention MOOCS) have shown - and as the responses to COVID-19 are further emphasising - a great deal of what a university does may be delivered, experienced, enjoyed, responded to, learned through and examined upon dominant digitally pedagogies blended (as appropriate) with face-to-face teaching strategies. It is as if established older terms like "digital", "virtual" and "online", as well as "distance education" and "remote learning" have been "discovered" by mainstream universities in their mainstream teaching! Accordingly, much or all of that may be shared, much as the entirety of Global School offerings may be common to all secondary and lifelong learners worldwide. When all of that has been done - what remains as necessary elements of the 'particular university', the 'individual institution'?

We predict that, post-pandemic, the following will in good time emerge:

1. a blended assessment and learning pedagogy in which digital is dominant above face-to-face; and

2. the one blended and universal University where worldwide access and organisation are dominant, yet integrated with local needs, cultures and priorities.

Such a University would be governed by professional association/government/international organisation Quality Assurance but still with individual institutions performing some key residual and localised roles. No longer myriad and competing businesses but now being responsible for enrolling their students and guiding them through the vast range of available self-learning materials (which certainly need not be institution-specific); monitoring progress, eventually providing formal certification as merited; arranging workshop experience at accredited outside venues (hospitals, construction sites etcetera); pastoral support; and research. Much in the manner of medieval Oxford during the 14th century Black Death, when the rival communities of scholars transmogrified into 'colleges' within the overall 'university'. But this time, with Digitisation, worldwide.

\section{References}

Collini, S. (2018). Speaking of Universities, Verso, London

Commonwealth of Learning (2020). Towards Resilient Education Systems Lessons from COVID-19. https://www.youtube.com/watch?v=NTfb4yprRPA

Douse, M. (1973, March 23). Let's be Open about Milton Keynes, Nation Review, Sydney: p. 17

Douse, M. \& Uys, P.M. (2020a). One World One School - Education's forthcoming fundamental transformation. Online: self -published. ISBN: 9798626785883; ASIN: B 0861B163X. http:// www.globeonline.com/oneworldoneschool.pdf

Douse, M. \& Uys, P.M. (2020b). Covid-19 and the demise of 'The School', NORRAG blog, June 2020

Jones, S. (2020, 31st March). Covid-19 is our best chance to change universities for good: Guardian 2020, 
https://www.theguardian.com/education/2020/mar/31/covid-19-is-our-best-chance-to-change-universitiesfor-good

Kwong, N. S. (2020, 27 March). When ICT 5.0 meets COVID-19: Are we ready for Flexible Teaching \& Learning? Learning Technologies, https://blog.ascilite.org/when-ict-5-0-meet-with-convid-19-are-we-readyfor-flexible-teaching-learning/

McAleavy, T \& Gorgen, K. (2020). What does the research suggest is best practice in pedagogy for remote teaching? https://inee.org/system/files/resources/remote-teaching.pdf

Oliver, M., \& Trigwell, K. (2005). Can 'Blended Learning' Be Redeemed? E-Learning and Digital Media, 2(1), 17-26. https://doi.org/10.2304/elea.2005.2.1.17

Stracke, C.M., Shanks, M. \& 27 March Tveiten, O. (2018). Smart Universities: Education's Digital Future, The World Learning Summit and LINQ Conference 2017 proceedings

UNESCO International Bureau of Education (2020). Multiple literacies. http://www.ibe.unesco.org/en/glossarycurriculum-terminology $/ \mathrm{m} /$ multiple-literacies

Uys, P.M. (2020). International reflections on lessons learned during the COVID 19 pandemic about ensuring quality in online assessment: Oceania, ICD E Quality Network Webinar: https://static1.squarespace.com/static/5b99664675f9eea7a3ecee82/t/5ee3309387a301684ca477cd/15919474 15662/Philip+Uys+ICDE+Presentation+Assessment.pdf

Uys, P. \& Douse, M. (2020). The post-pandemic blended university in the time of digitisation. In S. Gregory, S. Warburton, \& M. Parkes (Eds.), ASCILITE's First Virtual Conference. Proceedings ASCILITE 2020 in Armidale (pp. 201-207). https://doi.org/10.14742/ascilite2020.0104

Note: All published papers are refereed, having undergone a double-blind peer-review process.

The author(s) assign a Creative Commons by attribution licence enabling others to distribute, remix, tweak, and build upon their work, even commercially, as long as credit is given to the author(s) for the original creation.

(C) Uys, P. \& Douse, M. 2020 